\title{
Addendum: Fang, Q.; Maldague, X. A Method of Defect Depth Estimation for Simulated Infrared Thermography Data with Deep Learning. Appl. Sci. 2020, 10, 6819
}

\author{
Qiang Fang * (D) and Xavier. Maldague *
}

Citation: Fang, Q.; Maldague, X. Addendum: Fang, Q.; Maldague, X. A Method of Defect Depth Estimation for Simulated Infrared Thermography Data with Deep Learning. Appl. Sci. 2020, 10, 6819. Appl. Sci. 2021, 11 , 3451. https://doi.org/10.3390/ app11083451

Received: 29 March 2021

Accepted: 2 April 2021

Published: 12 April 2021

Publisher's Note: MDPI stays neutral with regard to jurisdictional claims in published maps and institutional affiliations.

Copyright: (C) 2021 by the authors Licensee MDPI, Basel, Switzerland. This article is an open access article distributed under the terms and conditions of the Creative Commons Attribution (CC BY) license (https:/ / creativecommons.org/licenses/by/ $4.0 /)$.
Computer Vision and Systems Laboratory, Department of Electrical and Computer Engineering, Université Laval, av de la Médecine, Québec, QC 1065, Canada

* Correspondence: qiang.fang.1@ulaval.ca (Q.F.); Xavier.Maldague@gel.ulaval.ca (X.M.)

The authors wish to make the following corrections to this paper: [1].

The original version of our article (Fang, Q.; Maldague, X. A Method of Defect Depth Estimation for Simulated Infrared Thermography Data with Deep Learning. 2020, 10, 6819) did not include the complete funding and acknowledgements. The authors wish to change the information in the Funding section and Acknowledgements section from:

Funding: This research received no external funding.

Acknowledgments: This research is conducted under the Tier One - Multipolar Infrared Vision Canada Research Chair (MIVIM) in the Department of Electrical and Computer Engineering at Laval University. Authors would also like to thank the Chinese Scholarship Council for their financial support and help.

to:

Funding: The financial support from the NSERC Discovery Grant program and of the Canada Foundation for Innovation (CFI) program is acknowledged.

Acknowledgments: This research is conducted under the Tier One - Multipolar Infrared Vision Canada Research Chair (MIVIM) in the Department of Electrical and Computer Engineering at Laval University. Authors would also like to thank the Chinese Scholarship Council for their financial support and help. We also express our deep gratitude to Mrs. Farima Abdollahi Mamoudan from our laboratory for her willingness to share her simulation infrared thermography results.

The authors apologize for any inconvenience caused. The authors state also that the scientific conclusions are unaffected.

\section{Reference}

1. Fang, Q.; Maldague, X. A Method of Defect Depth Estimation for Simulated Infrared Thermography Data with Deep Learning. Appl. Sci. 2020, 10, 6819. [CrossRef] 